Cad.Est.Ling., Campinas, (40):39-51, Jan./Jun. 2001

\title{
A RELEVÂNCIA DO CONTEXTO LINGÜÍSTICO NA AQUISIÇÃO DA FONOLOGIA E NOS DESVIOS FONOLÓGICOS DO DESENVOLVIMENTO: O EXEMPLO DA PALATALIZAÇÃO
}

\author{
CARMEN LÚCIA MATZENAUER-HERNANDORENA * \\ (Universidade Católica de Pelotas)
}

Focusing the palatalization of coronal stops, a study with children acquiring Brazilian Portuguese, in normal and deviant process, makes clear a significant influence of the linguistic context in the behavior of consonantal segments, causing phonetic effects of co-articulation. In the analysis of the data, theoretical model based in constraints, as Optimality Theory, and dynamic model, as Articulatory Phonology, show more consistency in the explanation of context dependent phenomenon, like palatalization, than Autosegmental Theory, that demands a mixed solution, with the use of rules and also the use of output constraints.

Em trabalho anterior que aliava a aquisição da fonologia ao comportamento das línguas naturais, no sentido de registrar a assimilação como uma regra de aplicação freqüente, observou-se uma diferença: enquanto a ocorrência da assimilação nas línguas é comum na forma de harmonia vocálica, no processo de aquisição da fonologia é predominante como harmonia consonantal (Matzenauer-Hernandorena 1999, p.51). Os dados de aquisição da fonologia do Português Brasileiro (PB) - tanto em se tratando de desenvolvimento normal como de desenvolvimento com desvios - têm referendado que os segmentos consonantais são mais suscetíveis às influências do ambiente lingüístico do que os segmentos vocálicos. As vogais têm o comportamento fonológico estabilizado em etapa desenvolvimental anterior à da aquisição do sistema consonantal da língua e os dados da aquisição do PB evidenciam que são segmentos que, desde estágios iniciais da aquisição, apresentam os fenômenos de neutralização e de harmonia da vogal média pretônica, idênticos aos verificados no sistema-alvo (Bisol 1981; Vieira 1997).

A presença de assimilações durante o processo de aquisição da fonologia da língua é evidência de que o contexto lingüístico se mostra condicionador do comportamento dos segmentos em diferentes etapas desenvolvimentais. Tendo-se um exemplo claro desse condicionamento na palatalização, o presente trabalho apresenta

* Agradeço ao CNPq, pelo apoio à pesquisa - Processo nº 523364/95-4.

Agradeço ao Prof. Jorge Walter da Rocha Espiga, pelo apoio na utilização do pacote VARBRUL. pesquisa.

Agradeço às Bolsistas de Iniciação Científica da UCPEL, pelo apoio no tratamento dos dados da 
três pontos fundamentais: (a) a caracterização da palatalização das plosivas coronais; (b) a relevância do contexto lingüístico no comportamento da palatalização, apresentando dados da aquisição da fonologia, normal e com desvios; e (c) a abordagem do fenômeno da palatalização das plosivas coronais com base em diferentes propostas teóricas.

Sendo incontestável que a palatalização das plosivas coronais é conseqüência de vogal adjacente, esse fenômeno presente em variedades do PB foi alvo de pesquisa que buscou verificar o papel do contexto lingüístico no processo de aquisição da fonologia da língua. $O$ estudo, realizado com 72 crianças, com idade entre 1:3 e 2:5, foi capaz de evidenciar o condicionamento lingüístico no emprego das consoantes africadas [t $\left.\int\right] \mathrm{e}$ [d3], decorrentes da referida palatalização. Submetidos os dados ao pacote computacional VARBRUL, comprovou-se serem a vogal [i] e o glide coronal [j] seguintes às plosivas $/ \mathrm{t} / \mathrm{e} / \mathrm{d} / \mathrm{os}$ determinantes da palatalização. Tomando-se a situação específica de $/ \mathrm{t} /$, os pesos relativos do referido contexto seguinte, como gatilhos da palatalização, foram: [i] .92; [j] 1.00. Exemplos da palatalização da plosiva coronal /t/ aparecem em (1), com a explicitação da idade da criança em anos: meses, dias.

(1)

$\begin{array}{lll}\text { leite } & \text { ['letfi] } & \text { (idade 1:4,6) } \\ \text { tirou } & \text { [tfi'o] } & \text { (idade 1:4,21) } \\ \text { presente } & \text { ['zet } \mathrm{i}] & \text { (idade 1:6,19) } \\ \text { iogurte } & \text { [u'gut } \mathrm{j} \text { ] } & \text { (idade 1:6,8) } \\ \text { sorvete } & \text { ['fet } \mathrm{i}] & \text { (idade 1:7,17) } \\ \text { forte } & \text { ['fojtfi] } & \text { (idade 1:9,2) }\end{array}$

À luz da Fonologia Autossegmental, a literatura da área pacificamente registra a palatalização das plosivas coronais como decorrente de assimilação, representada nesse modelo pelo espraiamento do traço [coronal] da vogal para a plosiva. Desse espraiamento, resulta a forma palatalizada $\left[\mathrm{t}^{\mathrm{j}}\right]$ (em se tratando da plosiva coronal [-sonora]), antes de ser criada a forma africada [t $\int$ ]. Pelo fato de toda vogal coronal ser [-anterior], o espraiamento desse traço vocálico acarreta que o traço [coronal] da articulação consonantal da plosiva também se torne [-anterior]. Para passar-se da consoante complexa $\left[\mathrm{t}^{\mathrm{j}}\right]$ para a africada $[\mathrm{t} \mathrm{f}]$, há o desligamento do traço menor, secundário [coronal], e ocorre a sua cópia sob o nó Ponto de Consoante, o que implica a promoção do traço secundário [coronal] à articulação primária (passa a ser dominado diretamente pelo nó Ponto de Consoante) e, depois, há a subseqüente cisão da consoante (Clements 1991; Clements \& Hume 1995; Bisol \& Hora 1993), fazendo surgir a consoante africada coronal palatal, considerada, por Clements \& Hume (1995) 
e por Calabrese (1995), consoante de contorno, apresentando uma borda com o traço [-contínuo] e outra com o traço [+contínuo], conforme mostra a representação (2).

(2)

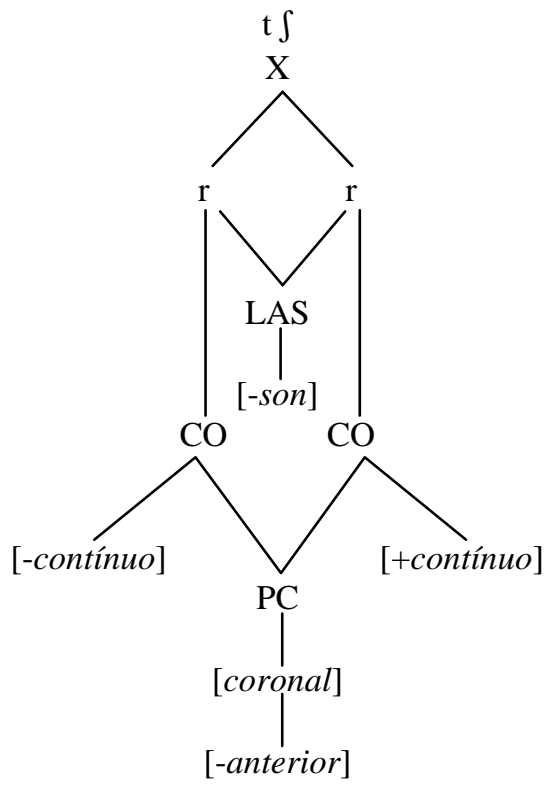

O fato de ser o segmento vocálico seguinte o desencadeador da palatalização da plosiva coronal comprova a inter-relação entre as melodias de segmentos em seqüência - nesse caso há a interação vogal-consoante -, evidenciando efeitos fonéticos de coarticulação.

Mas, além do contexto imediatamente seguinte à plosiva coronal, o tratamento estatístico dos dados apontou ainda outros grupos de fatores como fortes condicionantes da palatalização aqui referida, evidenciando também a interação consoante-consoante no processo de aquisição da fonologia, incluindo a influência da tonicidade, como mostram os dados em (3):

a) CONTEXTO SEGUINTE:

- palatal onset da sílaba seguinte - .74

Ex.: ratinho [a't $\int \tilde{y} u$ ] (idade 1:7:17)

patinho [pa't ĩnu] (idade 1:7,17)

- $\quad$ sibilante coronal onset da sílaba seguinte - .89

Ex.: tesoura [t $\mathrm{t} i$ 'zoa] (idade 2:2)

[t]i'zora] (idade 2:5,27) 
b) CONTEXTO PRECEDENTE:

- $\quad$ palatal onset da sílaba precedente - .99

Exs.:titia [t]i'tfia] (idade 1:4,6)

gente ['3ct]i] (idade 1:9,9)

- $\quad$ sibilante coronal onset da sílaba precedente - .85

Exs.: presente ['zet $\left.\int i\right]$ (idade 1:6,19)

[pe'zẽjn t $\mathrm{ti}$ ] (idade 1:8,12)

- $\quad$ sibilante coronal coda da sílaba precedente - .64

Exs.: este ['est $\left.\int \mathrm{i}\right]$ (idade 1:6,26)

revistinha [revis' tfĩna] (idade 2:4)

c) TONICIDADE:

- postônica final de palavra - .93

Exs.: leite ['let $\left.\int i\right]$ (idade 1:10,15)

sorvete ['fet $\mathrm{i}$ ] (idade 1:8)

Ao verificar-se que consoantes palatais, como onset de sílaba precedente e/ou seguinte, favorecem a palatalização das plosivas coronais, à luz da Fonologia Autossegmental pode evidenciar-se a interação consoante-consoante. Dessa interação, resultam consoantes em seqüência que passam a compartilhar o mesmo ponto de articulação, fato que, nesse modelo teórico, é representado pela interligação de estruturas melódicas, conforme é mostrado em (4), em decorrência do princípio conhecido como OCP (Obligatory Contour Principle/Princípio do Contorno Obrigatório), que pró́be elementos adjacentes iguais, causando ou o desligamento de um desses elementos ou o reconhecimento de sua unidade pela interligação dos elementos idênticos. Na verdade, essa é também uma forma de representação de um efeito de co-articulação.

Deve salientar-se que a Fonologia Autossegmental é uma teoria com base em regras e que uma forma que tem de resolver o efeito de co-articulação é com o OCP que, na realidade, é um tipo de restrição ao output linguiístico. Sob esse ângulo, portanto, uma saída que essa teoria encontra para o referido fenômeno é um mecanismo que a torna mista, ou seja, que a faz integrar regras e restrições a outputs. 
(4)

a) palatal onset da sílaba seguinte [pa't tĩnu] (patinho)

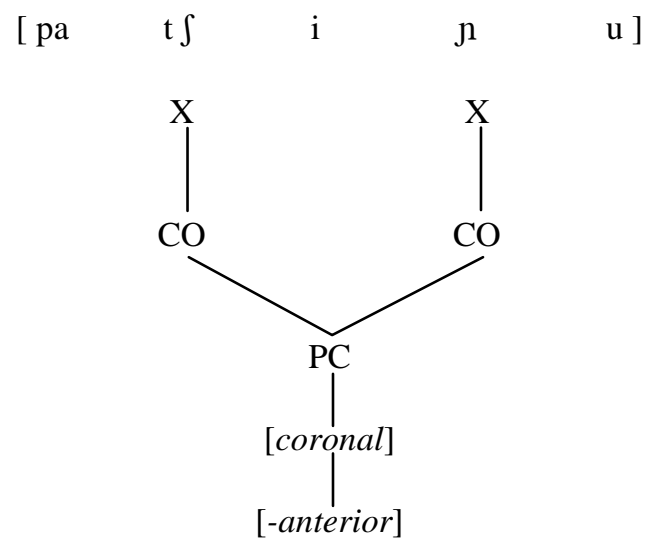

b) palatal onset da sílaba precedente ['zet $\mathrm{i}]$ (gente)

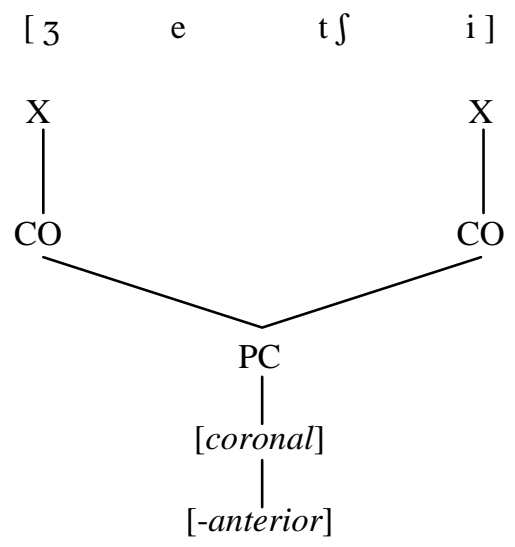

É também por efeito de co-articulação que sibilantes coronais onset de sílaba precedente e/ou seguinte, bem como sibilantes coronais coda de sílaba precedente favorecem a palatalização aqui referida. Pode-se afirmar que o traço [coronal] de segmentos vizinhos à plosiva coronal favorece a palatalização, ou seja, toda uma seqüência coronal circundante leva o /t/ a manifestar-se como [t $\int$ ], como resultado de co-articulação, sendo que a coronalidade do [i] seguinte desencadeia essa palatalização. Mas sendo o resultado da co-articulação representado nesse modelo por estruturas interligadas, em se tratando desse condicionamento tem de se registrar o resultado do OCP também no tier do traço [contínuo], conforme (5) pode mostrar. Nesse caso, é traço [+contínuo] das sibilantes coronais, compartilhado redundantemente pelas vogais, 
que parece também atuar, favorecendo que a borda direita da plosiva coronal se torne [+contínua]. Esse fato fica evidente quando a sibilante coronal aparece como onset da sílaba seguinte, como mostra (5).

(5) palatal onset da sílaba seguinte [tfi'zora] (tesoura)

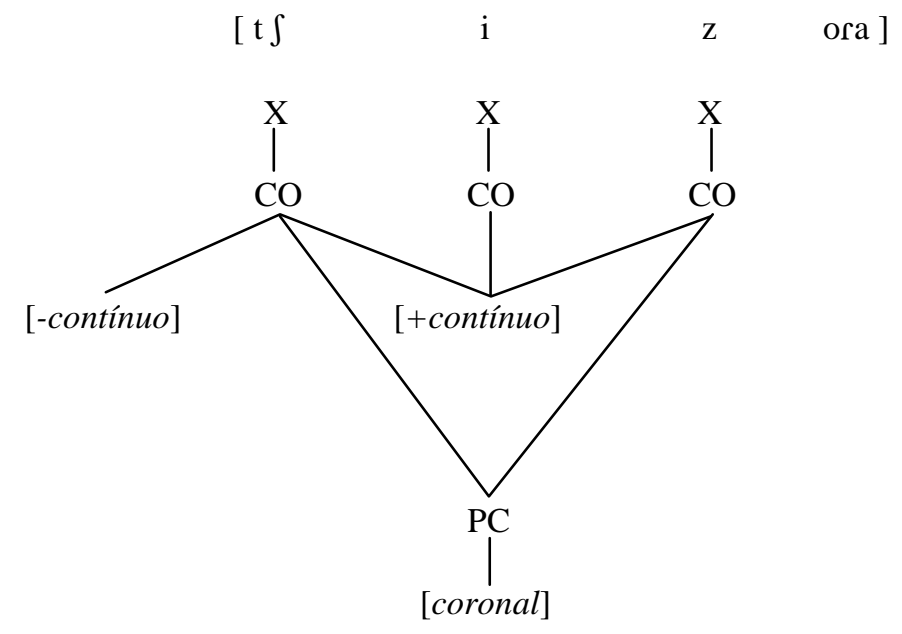

Mas é interessante observar que, nesse modelo, como há um princípio de boaformação que proíbe o cruzamento de linhas de associação, o tier do traço [contínuo] pode estar favorecendo a palatalização de /t/ somente no contexto seguinte à plosiva, uma vez que, no contexto precedente, em virtude de [t $\mathrm{t}]$ ter a borda esquerda [-contínua], os segmentos [+contínuos] nesse tier não podem a ele interligar-se, porque haveria cruzamento de linhas de associação. Então, seria pertinente a pergunta acerca de como se pode registrar, nesse modelo, o favorecimento da palatalização das plosivas coronais pela sibilante coronal em contexto anterior, seja como onset, seja como coda da sílaba precedente. Esse condicionamento só pode ser creditado à presença do traço [coronal]. O tier do traço [contínuo], no contexto precedente à africada, não pode estar atuando favoravelmente à sua realização. $\mathrm{E}$, pelos dados de aquisição da fonologia do Português, como se vê em (6) (e como se pode constatar em (3)), é tão frequiente o favorecimento para o emprego da palatalização com o contexto precedente constituído da seqüência vogal coronal + sibilante coronal coda da sílaba anterior - as quais têm o traço [+contínuo] - que pareceria estar também esse traço militando a favor da realização de [t $\int$ ]. No entanto, pela teoria, como já se disse, somente o traço [coronal], em se tratando do contexto precedente, pode estar favorecendo a africada palatal. 
(6)

$\begin{array}{ll}\text { este } & \left.\left.\text { ['est } \int \mathrm{i}\right] \text { (idade } 1: 6,26\right) \\ \text { sabonete } & \left.\left.\text { [savo'nest } \int \mathrm{i}\right] \text { (idade } 1: 11,15\right) \\ \text { revistinha } & \text { [revis't } \mathrm{t} \text { ina] (idade } 2: 4) \\ \text { triste } & \left.\text { [' } \mathrm{t} \text { [ist } \int \mathrm{i}\right] \text { (idade 2:5,27) } \\ & \left.\text { ['trist } \int \mathrm{i}\right] \text { (idade 2:4) }\end{array}$

Poderia argumentar-se que esse condicionamento lingüístico da palatalização das plosivas coronais se restringe ao funcionamento da língua em seu processo aquisicional, mas não é o que a realidade mostra: uma pesquisa de Albano $(1999$, p.151) concluiu que, mesmo em dialetos do PB não-africadores, é palatalizada a plosiva coronal diante de [i], quando a sílaba anterior apresenta vogal coronal, seguida de /s/, como em ['est $\mathrm{i}]$, ['Est $\left.\int \mathrm{i}\right]$ e ['ist $\left.\mathrm{i}\right]$.

Os resultados obtidos pelo tratamento estatístico referentemente ao contexto seguinte favorecedor da palatalização das plosivas coronais, mostrados em (3), e o seu funcionamento, representado em (5), poderiam estar atestando a existência efetiva de uma face [-contínua] e de outra [+contínua] nas palatais africadas, confirmando-lhes o status de consoantes de contorno; parecem mesmo ser segmentos que contêm duas raízes, com a sequiência [-contínuo] / [+contínuo] sob essas raízes, como preconizam Clements \& Hume (1995) e Calabrese (1995). Sendo assim, a formalização em (2) parece ser a adequada representação para os segmentos africados palatais [t $\mathrm{t}]$ e [d 3 , que resultam da regra de palatalização das plosivas coronais antes de [i] em muitas variantes do $\mathrm{PB}$.

Uma evidência para atribuição de uma borda [+contínua] para os segmentos africados e a confirmação de seu status de consoantes de contorno pode se colhida também em dados de aquisição do Inglês como língua materna, já que essa língua apresenta as africadas [t $\left.\int\right]$ e [dz] em seu sistema fonológico, embora nenhum dos autores de Língua Inglesa aqui referidos tenha apresentado os dados com essa interpretação. No processo de aquisição do Inglês, crianças empregam plosivas ou africadas correspondendo a alvos fricativos. Há exemplos desse emprego em vários dados pesquisados, como (7) apresenta:

(7)

a) dados de Amahl (idade 2:3 - 3:10), segundo Smith (1973):

$\begin{array}{ll}\text { 'goose' } & \text { [gu:ts }] \\ \text { 'send' } & {[\text { tsend }]} \\ \text { 'father' } & {[\text { fa:dzə }]} \\ \text { 'other' } & {[\Lambda \text { d }] \sim[\Lambda \text { dz }]} \\ \text { 'weasel' } & {[\text { wi:dzəl }]} \\ \text { 'closer' } & {[\text { kləutsə] }}\end{array}$


b) dados de Kevin (idade 1:6 - 1:9), segundo Edwards (1996):

'fish' [tis] [tzus]

'shoes' [tsju]

c) dados de Linda (idade 2:3), segundo Edwards (1996):

'zebra' ['dziba]

Ao empregarem consoantes plosivas ou africadas por seus sistemas não integrarem fricativas, essas crianças evidenciam o problema da instabilidade no emprego fonológico do traço [contínuo]. O uso da africada, que tem a borda direita [+contínua], se mostra, nesses casos, como um estágio intermediário entre a aquisição das plosivas (que são [-contínuas]) e a aquisição das fricativas (que são [+contínuas]), o que se comprova pelo fato de que as crianças cujos dados estão acima exemplificados, em lugar de fricativas [+anteriores], usaram africadas [+anteriores] - [ts] e [dz] -, que não integram o sistema fonológico do Inglês.

Retornando ao fato da influência do contexto na aquisição fonológica, vale referir que pesquisas sobre crianças com desvios fonológicos também são capazes de referendar a influência do contexto no uso de africadas em lugar de plosivas coronais. Um exemplo aparece nos dados de D., menina de 7 anos e 1 mês que apresenta preferência sistemática por um som (Yavas \& Matzenauer-Hernandorena 1991): seu sistema fonológico não apresentada fricativas, sendo que esses alvos são realizados regularmente como [t] em onset inicial de palavra e como [t $\left.\int\right]$ ou [d3] em onset átono intervocálico, ou seja, entre segmentos que apresentam o traço [+contínuo]. Em (8) estão exemplos da produção lingüística de D.

a) onset inicial

chapéu [ta'pew]

janela [ta'nela]

chave ['tat $\left.\int \mathrm{i}\right]$ b) onset intervocálico

bicho ['bit5u]

relógio [re'lodzju]

caixa ['ta t 5 ə]

Os dados dessa menina atestam o uso da africada palatal (que tem a borda direita [+contínua]), em lugar da plosiva, entre vocóides, ou seja, entre segmentos [+contínuos], sempre em sílabas átonas, particularmente precedendo vogais [-baixas].

Nesse ponto, é possível verificar-se que podem ser destacados, entre todos os dados até aqui apresentados, cinco fatos: a) o emprego das africadas palatais como decorrência da palatalização das plosivas coronais é conseqüência de processo de assimilação ou de co-articulação; b) essa palatalização é, como diz a literatura, um processo de coronalização, desencadeado pela vogal coronal [i] ou pelo glide coronal [j]; c) esse processo é favorecido por outros segmentos do contexto lingüístico circundante, que compartilham o traço [coronal]; d) o uso da africada palatal é favorecido em posição átona, à borda direita de um pé troqueu (os resultados relativos à variável tonicidade em (3) confirmam esse fato); e) a palatalização é representada, no 
modelo autossegmental, pelo espraiamento do traço coronal da vogal alta seguinte, sendo que o favorecimento da regra pelo contexto circundante é explicado com base no $\mathrm{OCP}$, que se constitui em uma restrição ao output.

E como pode ser visto esse efeito de co-articulação e de favorecimento da realização das africadas palatais à luz de um modelo teórico cuja relação entre input e output se faça somente com base em restrições e não com base em regras? Na Teoria da Otimidade, a escolha do output ótimo é realizada pela avaliação dos candidatos a output a partir da hierarquia de restrições estabelecida pelo sistema. As restrições são universais e consistem em requisitos estruturais que podem ser satisfeitos ou violados numa forma de output (Kager 1999, p.9). A violação às restrições deve ser mínima, ocorrendo somente para evitar violações a restrições mais altas na hierarquia. Como as restrições se manifestam na forma de asserções, sejam afirmativas ou negativas, o fenômeno da assimilação terá de ser assim também expresso; o importante é que terá de captar o espalhamento de um ou mais traços por determinado domínio. A literatura já registra restrições dessa natureza; Coronal/high (CORONAL/ALTO) (Kager 1999) pode ser entendida como um exemplo desse tipo de restrição.

Como simples exemplo do funcionamento da teoria, propõe-se aqui o uso de três restrições, que aparecem em (9), para ilustrar a ocorrência da palatalização das plosivas coronais.

a) Ident-IO (cor) - a especificação do ponto [coronal] de um segmento do input deve ser preservado no output.

b) Ident-IO (cont) - a especificação do valor do traço [contínuo] de um segmento do input deve ser preservado no output.

c) Coronal/alto - consoantes coronais que antecedem vogais coronais altas também são altas.

As restrições (a) e (b), que integram as restrições da família de Fidelidade entre input/output, preservam a manutenção do ponto [coronal] e da presença do traço [contínuo] no segmento palatalizado; a restrição (c) faz a plosiva coronal tornar-se palatal.

A hierarquia dessas restrições, conforme apresenta o tableau em (10), mostra como output ótimo para a plosiva coronal antes de [i] a forma com a africada palatal, apontando como subótima a forma não palatalizada ['tia].

\begin{tabular}{||c|c|c|c||}
\hline \hline /tia/ & $\begin{array}{c}\text { IDENT-IO } \\
\text { (cor) }\end{array}$ & $\begin{array}{c}\text { IDENT-IO } \\
\text { (cont) }\end{array}$ & COR/ALTO \\
\hline \hline 'tia & & & $*$ \\
\hline$\sigma$ 't 'ia & & & \\
\hline ' 'ia & & $* !$ & $*$ \\
\hline 'sai & & $* !$ & \\
\hline 'kia & $* !$ & & \\
\hline
\end{tabular}


Observe-se que, embora o segmento [t $\mathrm{f}]$ apresente dois valores para o traço [contínuo], não viola a restrição IDENT-IO (cont) porque sua estrutura interna também integra o valor [-contínuo] contido no segmento /t/.

A presença de outra restrição na hierarquia - da família ALINHAMENTO deverá referir a preferência, durante o processo de aquisição da fonologia da língua, pela palatalização na borda direita do pé troqueu. A inclusão desse tipo de restrição na hierarquia é capaz de representar um dos avanços da Teoria da Otimidade: o tratamento simultâneo de fenômenos de natureza melódica com os de natureza prosódica.

Uma vantagem desse modelo sobre o anteriormente referido é a consistência conceitual, uma vez que não mistura regras e restrições. Além disso, consegue reunir a base fonética do efeito de co-articulação em uma restrição estrutural, como a restrição CORONAL/ALTO, aqui exemplificada. Mas há outra vantagem dessa proposta teórica: a capacidade de generalização. Ao usar-se, por exemplo, a restrição CORONAL/ALTO, tem-se que qualquer consoante coronal tenderá a palatalizar-se antes da vogal alta [i]. Dessa forma é possível prever-se que /s/ e /z/ podem realizar-se como [J] e [3], respectivamente, antes de [i]. E é o que pode ocorrer no processo de aquisição da fonologia, como atestam pesquisas, como a de Matzenaeur-Hernandorena (1994), e é também o que ocorre no Inglês Americano (Hyman 1975:24-25): /t/, /d/, /s/ e /z/ realizam-se como [t $\mathrm{f}],[\mathrm{d} 3],\left[\int\right]$ e [3], respectivamente, antes do glide coronal [j]. Em razão do seu próprio formalismo, portanto, a Teoria da Otimidade, além de automaticamente bloquear ou promover outputs possíveis, pode captar maiores generalizações, mostrando boa capacidade preditiva.

Mas se os efeitos do contexto são fundamentais para a palatalização, é importante seguir-se ainda outro caminho, usando-se um modelo dinâmico, como a Fonologia Articulatória. A Fonologia Articulatória tem o gesto articulatório como unidade fônica abstrata, consistindo este, no dizer de Albano (1999, 2001), numa oscilação que afeta simultaneamente o curso temporal de vários parâmetros articulatórios, denominados variáveis do trato, os quais determinam, por sua vez, as trajetórias dos articuladores. Com esse fundamento teórico, o fenômeno aqui foco de estudo adquire outra feição e segue explicação também diferente, não mais com base em unidades como o fonema, o segmento, o traço ou qualquer autossegmento. As unidades não são mais estáticas; evoluem no tempo e são experimentadas e analisadas instrumentalmente, pois, como diz Albano (1999, p.156), um gesto pode reduzir-se (isto é, atuar como uma mola mais curta) ou diferentes gestos podem sobrepor-se (isto é, uma oscilação pode iniciar-se durante o curso de outra). De acordo com a Fonologia Articulatória, todos os processos fônicos das línguas do mundo devem-se à ação ou interação desses dois mecanismos: a redução e a sobreposição.

Com esse entendimento, para Albano (1999), a palatalização das plosivas coronais, como outras alterações segmentais que se registram no $\mathrm{PB}$, não é uma mudança categórica em que /t/ passa para a africada palatal: é um processo gradual, decorrente de variações contínuas da extensão e do tempo relativo aos movimentos articulatórios e que, por isso, é muito mais adequadamente representado por um modelo dinâmico, como a Teoria da Ação, que integra fonologia e fonética, o discreto e o contínuo. Albano (op.cit.) comprova, com os espectros da liberação da consoante 
plosiva /t/ em diferentes contextos, que em determinados ambientes (como em ['ist $\int \mathrm{i}$ ] quando o [t] é seguido por [i] e precedido por vogal coronal, seguida de [s]), essa plosiva se torna, em falantes de dialeto não-africador, tão palatalizada como a de falantes africadores, como se vê em (11 b), comparando-se com a africada [t $\int$ ] em (11 a).

Na verdade, com esse exemplo, Albano explicita também a relevância do contexto lingüístico no emprego de segmentos quando refere textualmente que "fica claro que os falantes de dialetos não-africadores precisam de outros fatores, além de um [i] seguinte, para deslanchar a palatalização". E ressalta que "quando esses fatores se acumulam, o processo, surpreendentemente, torna-se audível". Conclui, portanto, que "o discreto e o contínuo convivem lado a lado" (1999, p.153).

(11)

Espectros da liberação da consoante em:

a) $\left[\mathrm{t} \int\right] \mathrm{a}$

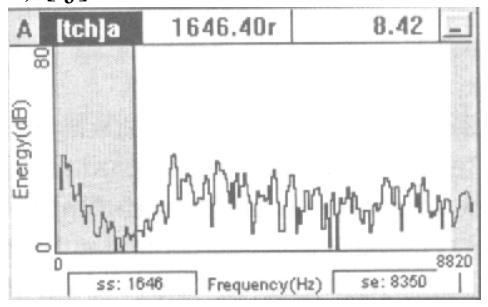

b) is[t]e (falante não-africador)

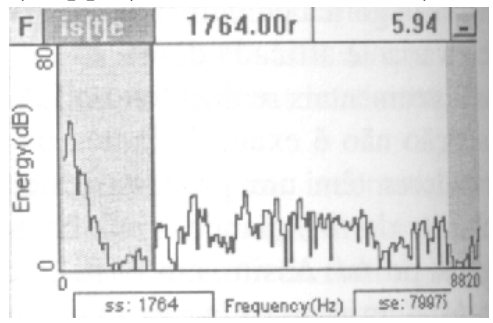

Comparando-se os espectros em (a) e (b), vê-se que são extremamente semelhantes, pois os dois mostram-se, como ressalta Albano (1999, p.151), compactos e ascendentes. Para registrar a diferença com [t], Albano mostra que o espectro dessa consoante é, ao contrário, difuso e descendente, como se vê em (12).

Espectro da liberação da consoante em [t]a:

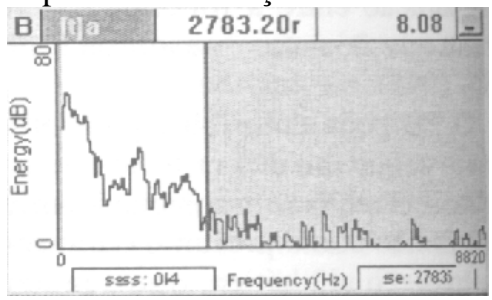

Com esse estudo, diz Albano (1999, p.157) que a palatalização ocorre gradientemente em dialetos não-africadores, com saliência no contexto em que [t] é seguido de [i] e precedido de vogal coronal seguida de [s], porque "a semelhança entre 
vogais de sílabas adjacentes favorece a sua sobreposição, fazendo com que as consoantes coronais, empurradas por ambos os gestos vocálicos, flutuem sobre as vogais anteriores, palatalizando-se". E isso ocorre predominantemente em sílabas átonas, como a postônica não-final no vocábulo lingüística, por exemplo, "porque a batida ritmicamente fraca dos proparoxítonos favorece o deslizamento da consoante sobre a coda do gesto da vogal tônica e essa posição favorece a redução do gesto consonantal, provocando o enfraquecimento da obstrução". Ao concluir esse comportamento não só para as plosivas coronais, o presente modelo está prevendo que a palatalização tenderá a acontecer com outras consoantes coronais em contexto idêntico. A capacidade de generalização da proposta, portanto, é indiscutível.

Os exemplos referidos por Albano (1999) atestam claramente a influência do ambiente lingüístico na fonologia e a conseqüente gradiência de sua manifestação em muitos fenômenos, como o da palatalização. Evidenciam que, então, é fundamentalmente a seqüência da coronalidade que favorece a palatalização da plosiva coronal, o que vem, em certo sentido, confirmar a coerência das conclusões representadas em estruturas autossegmentais em (4) e em (5) e, pela Teoria da Otimidade, vem corroborar a pertinência do funcionamento, na hierarquia de restrições do PB, da restrição CORONAL/ALTO, como (10) evidencia.

O trabalho leva a concluir-se que, na busca permanente de descrições acuradas e de explicações consistentes para os fenômenos da aquisição da fonologia e de desvios fonológicos do desenvolvimento, as pesquisas estão apontando para a necessidade crescente de atenção especial aos contextos lingüísticos dos dados estudados, seja na proposição de testes de avaliação, seja na análise dos corpora obtidos. Além disso, fundamental é atentar para o embasamento teórico da análise - nem todos os modelos teóricos têm a mesma capacidade explanatória e preditiva -, e é basilar lembrar que os estudos não têm de vincular-se (ou não podem) a um único modelo, devendo-se procurar muitas vezes, em virtude da realidade multifacetada da língua, mais de uma teoria; não se deve esquecer que a expressão externa da linguagem é articulada e que, portanto, fonética e fonologia têm de ser aliadas num estudo que se quiser completo, particularmente em se tratando de aquisição da linguagem, seja em caso de processo considerado normal, ou em caso de desvio do desenvolvimento fonológico.

\section{REFERENCIAS}

ALBANO, E.C. (1999). O gesto articulatório como unidade fônica abstrata: indícios da fala infantil e evidências da fala adulta. In: LAMPRECHT, R.R. (org.) Aquisição da linguagem: questões e análises. Porto Alegre: EDIPUCRS.

. (2001). O Gesto e suas Bordas - esboço de fonologia acústico-articulatória do Português Brasileiro. Campinas: Mercado de Letras/ALB/FAPESP.

BISOL, L. (1981). Harmonização vocálica. Tese de Doutorado. Rio de Janeiro: UFRJ.

BISOL, L. \& HORA, D. da. (1993). Palatalização da oclusiva dental e fonologia lexical. Actas do IX Encontro da Associação Portuguesa de Lingüística. Coimbra: APL, 1993. 
CALABRESE, A. (1995). A constraint-based theory of phonological markedness and simplification procedures. Linguistic Inquiry, v.26, n.3, p.373-463.

CLEMENTS, G. (1991). Place of articulation in consonants and vowels: a unified theory. Working Papers of the Cornell Phonetics Laboratory, n.5, p.77-123.

CLEMENTS, G. \& HUME, E. (1995). The internal organization of speech sounds, In: GOLDSMITH, J. (ed.) The Handbook of Phonological Theory. Cambridge: Blackwell Publishers, p.245-306.

EDWARDS, M.L. (1996). Word position effects in the production of fricatives. In: BERNHARDT, B.; GILBERT, J.; INGRAM, D. (eds.) Proceedings of the UBC International Conference on Phonological Acquisition. Somerville: Cascadilla Press.

HYMAN, L.M. (1975). Phonology: Theory and Analysis. New York: Holt, Rinehart and Winston.

KAGER, R. (1999). Optimality Theory. Cambridge: Cambridge University Press.

MATZENAUER-HERNANDORENA, C.L. (1994). A geometria de traços na representação das palatais na aquisição do Português. Letras de Hoje. Porto Alegre: PUCRS, v.29, n.4, p. 159-167.

(1999). Tendências dos estudos em aquisição da fonologia do Português Brasileiro: a pertinência dos modelos gerativos. Letras de Hoje. Porto Alegre: PUCRS, v. 34, n. 3, p. 41-63.

SMITH, N.V. (1973). The acquisition of phonology: a case study. Cambridge: Cambridge University Press.

VIEIRA, M.J.B. (1997). Aspectos do sistema vocálico do Português. Tese de Doutorado. Porto Alegre: PUCRS.

YAVAS, M. \& MATZENAUER-HERNANDORENA, C.L. (1991). Systematic sound preference in phonological disorders: a case study. Journal of Communication Disorders. New York: v.24, p.79-87. 